\title{
TREN PENCATATAN LAPORAN CAKUPAN KUNJUNGAN K4 PUSKESMAS DI DINAS KESEHATAN KOTA SURABAYA TAHUN 2015-2017
}

\author{
TRENDS IN RECORDING REPORTS ON THE COVERAGE OF \\ K4 VISITS AT PUBLIC HEALTH CENTER IN SURABAYA CITY \\ HEALTHCARE OFFICE FOR 2015-2017
}

\author{
Siti Rohmatun Ni'mah' ${ }^{1}$, Soenarnatalina Melaniani ${ }^{2}$ \\ ${ }^{1,2}$ Departemen Biostatistika dan Kependudukan \\ Fakultas Kesehatan Masyarakat Universitas Airlangga \\ Jl. Mulyorejo Kampus C Unair Surabaya, Jawa Timur 60115, Indonesia \\ Alamat Korespondensi: Siti Rohmatun Ni'mah \\ E-mail: siti.rohmatun.nimah-2015@fkm.unair.ac.id
}

\begin{abstract}
One of the management of health information systems are reported and processed like data regarding coverage of K4 pregnant women. The coverage visited of pregnant women Surabaya in 2017 is 98.55\% of 47,104 pregnant women. That indicator has been used assess maternal and child health services. This can be identified by the completed coverage of antenatal care (supply service standards and keeping the time set), which describes the ability of management or continuity of the maternal and child health program. The study was carried out to describe the trend of the coverage report system K4 pregnant woman visits at the Surabaya City Health Office in 2015-2017. This research is a descriptive study with a quantitative approachment, the data used by secondary data from the Surabaya City Health Profile Report from 2015 to 2017. The data were based on coverage of K4 pregnant women from 2015 to 2017, there are several public health centers with report trends visits to K4 pregnant women which tend to declined and less than the target of $98.45 \%$ that have been fixed in the Strategic Plan of Surabaya City Health Office. Three health center whose trend of data has decreased from 2014-2017 are Tembok Dukuh Health Center, Simokerto Health Center, and Menur Health Center. This is due to an error in the reporting mechanism both in data input, data processing, and output, it is necessary to develop an information system for recording and reporting on maternal health services, especially for pregnant women and evaluating reports on K4 pregnant women's visits.
\end{abstract}

Keywords: K4 visit scope, pregnant women, report trends

\begin{abstract}
ABSTRAK
Salah satu pengelolaan sistem informasi kesehatan adalah data pelaporan yang dikumpulkan dan diolah seperti data mengenai cakupan kunjungan ibu hamil K4. Cakupan kunjungan ibu hamil di Kota Surabaya pada tahun 2017 yaitu mencapai 98,55\% dari 47.104 ibu hamil. Penelitian ini untuk mendeskripsikan tren laporan cakupan kunjungan ibu hamil K4 Puskesmas di Dinas Kesehatan Kota Surabaya tahun 2015-2017. Cakupan kunjungan ibu hamil K4 merupakan indikator penilaian pelayanan kesehatan ibu dan anak. Indikator tersebut dapat diketahui dengan cakupan pelayanan antenatal secara lengkap (memenuhi standar pelayanan dan menepati waktu yang ditetapkan), yang menggambarkan kemampuan manajemen ataupun kelangsungan program KIA. Penelitian ini merupakan penelitian deskriptif dengan pendekatan kuantitatif, data yang digunakan yaitu dengan menggunakan data sekunder dari Laporan Profil Kesehatan Kota Surabaya pada tahun 2015 hingga 2017. Berdasarkan uraian olahan data cakupan kunjungan ibu hamil K4 mulai tahun 2015 hingga 2017, terdapat beberapa puskesmas dengan tren laporan kunjungan ibu hamil K4 yang cenderung menurun dan kurang dari target 98,45\% yang telah ditetapkan pada Rencana Strategis (Renstra) Dinas Kesehatan Kota Surabaya. Tiga puskesmas dengan tren data yang mengalami penurunan dari tahun 2014-2017 yaitu Puskemas Tembok Dukuh, Puskesmas Simokerto, dan Puskesmas Menur. Hal ini disebabkan karena terjadi kesalahan dalam mekanisme pelaporan baik dalam input data, proses pengolahan
\end{abstract}


data, dan outputnya, sehingga perlu adanya pengembangan sistem informasi pencatatan dan pelaporan pelayanan kesehatan ibu terutama ibu hamil dan evaluasi laporan kunjungan ibu hamil K4.

Kata kunci: cakupan kunjungan K4, ibu hamil, tren laporan

\section{PENDAHULUAN}

Sistem Informasi Kesehatan (SIK) merupakan dasar untuk mengambil sebuah keputusan dan mempunyai empat fungsi dasar yaitu pembuatan data, kompilasi data, analisis data, sintesis, dan komunikasi serta penggunaan (Diana \& Setiawati, 2011). Sistem Informasi Kesehatan merupakan pengumpulan data dari sektor kesehatan dan beberapa sektor yang berfungsi untuk menganalisis data, memastikan kualitas keseluruhan, relevansi data, ketepatan waktu, dan untuk mengubah data menjadi sumber informasi sebagai pengambilan suatu keputusan terkait masalah kesehatan (WHO, 2010).

Sistem Informasi Kesehatan dalam peraturan perundang-undangan terdapat pada Keputusan Menteri Kesehatan Nomor 932 Tahun 2002 Tentang Petunjuk Pelaksanaan Pengembangan Sistem Informasi Kesehatan Kabupaten/Kota. Peraturan lain yang mengatur SIK yaitu terdapat pada Keputusan Menteri Kesehatan Nomor 004 Tahun 2003 Tentang Kebijakan dan Strategi Desentralisasi Bidang Kesehatan, yaitu kebutuhan akan data dan informasi tentang kesehatan yang dilakukan melalui data yang dikumpulkan akan diolah dan dianalisis hingga menghasilkan penyajian data dalam bentuk informasi.

Instansi yang menangani masalah informasi kesehatan salah satunya yaitu Dinas Kesehatan. Dinas Kesehatan merupakan suatu badan pemerintah yang memiliki kewajiban untuk melaksanakan beberapa tugas pemerintahan daerah dengan asas tugas untuk pembantuan dan memiliki fungsi untuk membuat suatu kebijakan secara teknis pada bidang kesehatan.

Aspek yang mempengaruhi kinerja Dinas Kesehatan Kota atau Kabupaten salah satunya adalah aspek tentang manajemen di bidang kesehatan. Dinas Kesehatan (Dinkes) Kota atau Kabupaten memiliki kewajiban untuk melakukan pengolahan data dan menyajikan berbagai informasi yang didapatkan dari sektor puskesmas, rumah sakit, maupun sektor sarana pelayanan kesehatan lain.

Informasi didapatkan dari hasil pengelolaan data. Informasi adalah data yang sudah dilakukan pengolahan untuk menjadi suatu bentuk yang lebih relevan dan berarti untuk yang membutuhkannya, sedangkan data yaitu suatu sumber berupa informasi yang memberikan gambaran tentang hasil dari pengolahan data (Mulyanto, 2009). Pengertian lain tentang informasi yaitu data yang sudah dilakukan pengorganisasian dan memiliki relevansi bagi yang menerimanya (Krismiaji, 2015).

Data dikumpulkan dan diolah oleh Dinas Kesehatan menjadi informasi salah satunya yaitu data cakupan kunjungan K4. Data cakupan kunjungan K4 menjadi salah satu data yang diolah oleh Pelayanan Kesehatan Ibu dan Anak (KIA) Dinas Kesehatan. Data cakupan kunjungan K4 sangat diperlukan untuk mengetahui cakupan dari ibu hamil yang mendapatkan pelayanan pemeriksaan kehamilan selama empat kali.

Proses pelayanan kehamilan ibu diberikan dalam rentang usia kehamilan yang dibagi menjadi 3 yaitu trimester 1 , trimester 2 dan trimester 3. Pelayanan pada ibu hamil harus dapat memenuhi jumlah frekuensi pelayanan minimal pada setiap trimester, antara lain minimal 1 kali pada trimester 1 (dengan usia hamil $0-12$ minggu), minimal 1 kali pada trimester 2 (dengan usia hamil 12-24 minggu), dan minimal 2 kali pada trimester 3 (dengan usia hamil 24 minggu sampai dengan waktu persalinan (Kemenkes RI, 2018).

Pelayanan kesehatan ibu hamil merupakan pelayanan antenatal berkualitas yang berguna untuk mendeteksi adanya risiko yang terjadi pada masa kehamilan. Pelayanan yang dilakukan yaitu memberikan akses terkait perawatan kehamilan yang berkualitas agar ibu hamil dapat memperoleh kesempatan untuk melakukan deteksi secara dini terhadap kasus komplikasi 
yang mungkin terjadi pada kehamilan sehingga kejadian kematian maternal dapat dilakukan pencegahan.

Pelayanan antenatal care memiliki frekuensi pelayanan kesehatan ibu hamil yang penilaiannya dilihat pada cakupan kunjungan K1 dan kunjungan K4. Cakupan kunjungan K1 merupakan total ibu hamil dengan perolehan pelayanan antenatal pada pertama kali kunjungan dengan tenaga kesehatan dibandingkan dengan total sasaran ibu hamil yang ada di wilayah kerja puskesmas per satu tahun. Cakupan kunjungan K4 merupakan total ibu hamil yang mendapatkan pelayanan antenatal yang tepat dengan standar minimal 4 kali sesuai jadwal yang ditetapkan pada tiap trimester yang dibandingkan dengan total sasaran ibu hamil di wilayah kerja puskesmas per satu tahun (Kemenkes RI, 2018).

Cakupan kunjungan $\mathrm{K} 4$ adalah cakupan ibu hamil yang memperoleh pelayanan antenatal sesuai standar yang ditentukan. Sesuai Peraturan Menteri Kesehatan Republik Indonesia Nomor 43 Tahun 2016 Tentang Standar Pelayanan Minimal Bidang Kesehatan, standar kunjungan K4 minimal dilakukan 4 kali dengan pembagian waktu yaitu 1 kali di trimester kesatu, 1 kali di trimester kedua dan 2 kali di trimester ketiga disuatu wilayah kerja puskesmas pada waktu tertentu. WHO juga menjelaskan bahwa ibu hamil yang mendapatkan pelayanan antenatal harus melakukan minimal $4 \mathrm{x}$ kunjungan selama kehamilan, yaitu $1 \mathrm{x}$ di trimester pertama, $1 \mathrm{x}$ di trimester kedua dan $2 \mathrm{x}$ di trimester ketiga. Pelayanan tersebut dilakukan guna memantau kesehatan dari ibu maupun janin yang dikandung dengan saksama untuk dapat dilakukan deteksi dini dan dapat diberikan intervensi dengan cara yang tepat apabila terjadi kondisi buruk (WHO, 2010).

Indikator tersebut dapat mengetahui pentingnya sistem pelaporan cakupan kunjungan K4 dengan lengkap yang memenuhi standar pelayanan serta dapat sesuai dengan ketetapan waktu yang diberikan. Indikator tersebut dapat memberikan gambaran tentang tingkat perlindungan terhadap ibu hamil pada suatu wilayah yang dapat digambarkan dengan kemampuan pada manajemen dan kelangsungan pada program KIA.
Cakupan kunjungan ibu hamil K4 di Indonesia pada tahun 2017 mencapai 87,3\%. Capaian tersebut meningkat dari tahun sebelumnya dibandingkan target dari Rencana Strategi (Renstra) Kementerian Kesehatan Republik Indonesia tahun 2017 yaitu sebesar $76 \%$. Capaian cakupan kunjungan K4 di Indonesia telah mencapai target (Kemenkes RI, 2018).

Data dari Profil Kesehatan Provinsi Jawa Timur pada tahun 2017 menunjukkan bahwa cakupan kunjungan ibu hamil K4 mencapai persentase $89,9 \%$. Cakupan kunjungan ibu hamil $\mathrm{K} 4$ tersebut meningkat dibandingkan pada tahun 2016 yang capaiannya $89,53 \%$. Cakupan kunjungan ibu hamil K4 di tahun 2016 mengalami penurunan dibandingkan pada tahun 2015 yaitu mencapai 91,24\% (Dinkes Provinsi Jawa Timur, 2017).

Provinsi Jawa Timur merupakan provinsi yang capaian kunjungan pada ibu hamil K4 belum mencapai target. Indikator K4 termasuk indikator Standar Pelayanan Minimal (SPM) dengan target $100 \%$. Hal tersebut dikarenakan terdapat $38 \mathrm{Kabupaten/Kota}$ yang belum dapat mencapai target sebab masih banyak ibu hamil yang tidak melakukan kunjungan dengan petugas kesehatan di trimester 1 (K1 Murni), sehingga perlu untuk dilakukan upaya dengan kunjungan rumah secara intensif oleh bidan, kemitraan bidan maupun dukun yang ada di suatu wilayah.

Capaian kunjungan ibu hamil K4 tertinggi pada Provinsi Jawa Timur dimiliki oleh Kabupaten Sidoarjo yakni sebesar 99,6\%, Kota Madiun 99,6\%, Kota Surabaya 98,5\%. Capaian yang terendah dimiliki oleh Kabupaten Bangkalan yakni sebesar 77,6\%, Kabupaten Nganjuk 79,9\%, Kabupaten Jember 81,1\% (Dinkes Provinsi Jawa Timur, 2017).

Kota Surabaya memperoleh peringkat ketiga dalam capaian kunjungan ibu hamil K4. Profil Kesehatan Kota Surabaya menjelaskan bahwa cakupan kunjungan ibu hamil K4 di Kota Surabaya tahun 2017 mencapai 98,55\%. Hal tersebut dapat diartikan bahwa kunjungan ibu hamil K4 Kota Surabaya sudah berhasil memenuhi target $98,45 \%$ yang merupakan target kinerja Dinas Kesehatan Kota Surabaya (Dinkes Kota Surabaya, 2018). 
Target yang dicapai telah meningkat dari tahun sebelumnya. Tingginya capaian yang diperoleh Kota Surabaya pada cakupan kunjungan ibu hamil dikarenakan terdapat puskesmas yang mengalami peningkatan, namun masih juga terdapat beberapa puskesmas yang masih dibawah target dari Rencana Strategis (Renstra) Dinas Kesehatan Kota Surabaya.

Berdasarkan uraian diatas, penelitian ini bertujuan untuk mengetahui gambaran laporan cakupan kunjungan ibu hamil K4 Puskesmas di Dinas Kesehatan Kota Surabaya tahun 20152017.

\section{METODE PENELITIAN}

Penelitian ini adalah penelitian deskriptif yang dilakukan dengan pendekatan kuantitatif. Penelitian ini bersifat non reaktif (Maharani \& Sulistyo, 2016). Teknik pengumpulan data didapatkan dari data sekunder, data yang digunakan yaitu Laporan dari Profil Kesehatan Kota Surabaya pada Tahun 2015 hingga 2017 yang terdapat di Dinas Kesehatan (Dinkes) Kota Surabaya. Penelitian menggunakan total populasi yaitu sebanyak 63 Puskesmas yang ada di Surabaya.

\section{HASIL PENELITIAN}

Hasil olahan statistik data dari cakupan kunjungan ibu hamil K4 di Kota Surabaya tahun 2015 yaitu mencapai $98,41 \%$ dari 47.095 ibu hamil yang berada di Kota Surabaya. Cakupan tertinggi di tahun 2015 yaitu Puskesmas Lidah Kulon sebesar $101,97 \%$ dari 302 ibu hamil, Puskesmas Sememi sebesar 101,13\% dari 1.076 ibu hamil, Puskesmas Simomulyo sebesar $100,45 \%$ dari 1.119 ibu hamil. Puskesmas yang terendah cakupan kunjungan $\mathrm{K} 4$ pada tahun 2015 yaitu Puskesmas Wonokusumo sebesar $54,95 \%$ dari 555 ibu hamil, Puskesmas Kenjeran 66,81\% dari 479 ibu hamil, Puskesmas Pegirian sebesar 67,26\% dari 756 ibu hamil (Dinkes Kota Surabaya, 2016).

Hasil olahan statistik data cakupan kunjungan ibu hamil di Kota Surabaya pada tahun 2016 yaitu mencapai $98,48 \%$ dari 47.480 ibu hamil. Cakupan tertinggi pada tahun 2016 yaitu Puskesmas Kalirungkut sebesar 103,26\% dari 887 ibu hamil, Puskesmas Sememi sebesar $100,68 \%$ dari 1.041 ibu hamil, Puskesmas Klampis Ngasem sebesar 100,26\% dari $390 \mathrm{ibu}$ hamil. Puskesmas yang terendah yaitu Puskesmas Tambakrejo sebesar 61,69\% dari 562 ibu hamil, Puskesmas Tembok Dukuh sebesar 62,51\% dari 582 ibu hamil dan Puskesmas Wonokusumo sebesar 70,53\% dari 857 ibu hamil (Dinkes Kota Surabaya, 2017).

Hasil olahan statistik data cakupan kunjungan ibu hamil di Kota Surabaya di tahun 2017 yaitu mencapai 98,55\% dari jumlah 47.104 ibu hamil. Hal ini berarti bahwa cakupan kunjungan ibu hamil K4 Kota Surabaya sudah berhasil memenuhi target $98,45 \%$ yang merupakan target kinerja Dinas Kesehatan Kota Surabaya. Target yang telah dicapai telah meningkat dari tahun sebelumnya sebagaimana dijelaskan pada Gambar 1.

Gambar 1 menunjukkan bahwa peningkatan cakupan kunjungan $\mathrm{K} 4$ yang didapat dari tahun 2015-2017 dapat dilihat bahwa kinerja dalam kunjungan ibu hamil K4 berhasil. Keberhasilan kinerja didukung oleh Puskesmas yang mengalami peningkatan pada cakupan kunjungan ibu hamil K4. Cakupan yang tertinggi di tahun 2017 yaitu Puskesmas Mulyorejo sebesar 104,06\% dari 692 ibu hamil, Puskesmas Kedungdoro sebesar 103,11\% dari $629 \mathrm{ibu}$ hamil, Puskesmas Gading sebesar 102,39\% dari 1.498 ibu hamil. Capaian yang lebih dari 100\% dikarenakan terdapat ibu hamil pendatang dari

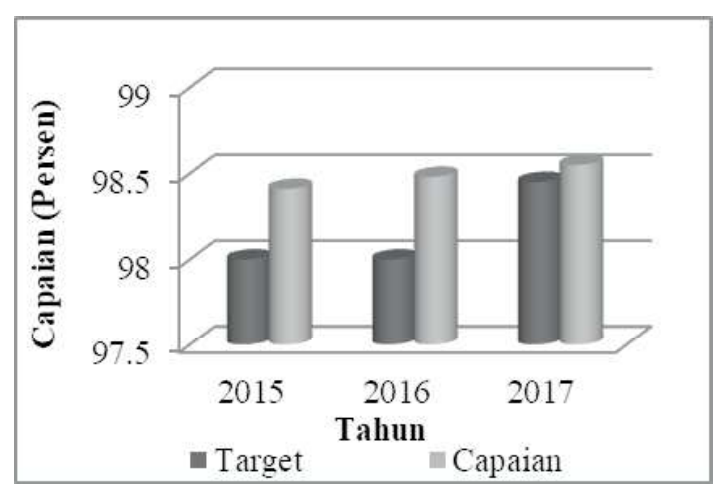

Gambar 1. Cakupan Kunjungan Ibu Hamil K4 di Kota Surabaya Tahun 20152017 
daerah lain yang memeriksakan kehamilannya di Surabaya, sehingga jumlah kunjungan K4 ibu hamil lebih banyak dari target capaian.

Puskesmas dengan capaian kunjungan K4 lebih dari $100 \%$ juga dapat dikarenakan beberapa hal, diantaranya akses yang diperoleh masyarakat pada pelayanan kesehatan ibu hamil oleh tenaga kesehatan cukup baik sehingga kunjungan K4 meningkat. Hal lain yang dapat menyebabkan kunjungan K4 lebih dari $100 \%$ yaitu sistem pencatatan dan pelaporan kunjungan $\mathrm{K} 4$ yang masih dilakukan secara manual, sehingga bisa terjadi kesalahan perhitungan sasaran ibu hamil tidak sesuai dengan jumlah dari ibu hamil di wilayah kerja puskesmas yang bersangkutan sehingga dapat mempengaruhi cakupan kunjungan K4 (Izati, 2018).

Puskesmas yang capaian kunjungan K4 terendah tahun 2017 yaitu Puskesmas Tambakrejo sebesar $64,14 \%$ dari 551 ibu hamil, Puskesmas Menur sebesar 66,93\% dari 587 ibu hamil, Puskesmas Tembok Dukuh sebesar $69,42 \%$ dari 606 ibu hamil (Dinkes Kota Surabaya, 2018). Puskesmas terendah cakupan kunjungan ibu hamil K4 termasuk puskesmas yang masih kurang dari target Dinas Kesehatan Kota Surabaya 98,45\% untuk tahun 2017.

Berdasarkan uraian olahan data cakupan kunjungan ibu hamil K4 mulai 2015 hingga 2017, puskesmas yang menempati peringkat tertinggi tidak selalu konsisten mempertahankan capaiannya hingga tahun 2017. Puskesmas yang menempati peringkat terendah bisa meningkatkan capaiannya meskipun masih di peringkat terendah.

Kota Surabaya memiliki 63 puskesmas, dari beberapa puskesmas di Kota Surabaya secara berturut-turut yaitu dari tahun 20152017, terdapat beberapa puskesmas dengan tren kunjungan ibu hamil $\mathrm{K} 4$ yang cenderung menurun dan kurang dari target $98,45 \%$ yang telah ditetapkan pada Rencana Strategis (Renstra) Dinas Kesehatan Kota Surabaya. Tiga puskesmas yang mengalami penurunan dari tahun 20142017 yaitu Puskemas Tembok Dukuh, Puskesmas Simokerto, dan Puskesmas Menur.

Tabel 1 menunjukkan bahwa Kota Surabaya memiliki tiga Puskesmas dengan ketidakstabilan capaian kunjungan ibu hamil K4. Data tersebut diambil berdasarkan laporan Profil Kesehatan Kota Surabaya pada tahun 2015-2017. Kecamatan Bubutan dengan Puskesmas Tembok Dukuh memperoleh capaian kunjungan K4 pada tahun 2015 sebesar 73,04\% dengan total 642 ibu hamil, menurun pada tahun 2016 sebesar $62,51 \%$ dengan total 582 ibu hamil, meningkat pada tahun 2017 sebesar $69,42 \%$ dengan total 606 ibu hamil. Kecamatan Simokerto dengan Puskesmas Tambak Rejo memperoleh capaian kunjungan K4 pada tahun 2015 sebesar 77,04\% dengan total $604 \mathrm{ibu}$ hamil, menurun pada tahun 2016 sebesar $61,69 \%$ dengan total 562 ibu hamil, meningkat pada tahun 2017 sebesar 64,14\% dengan total $551 \mathrm{ibu}$ hamil. Kecamatan Sukolilo dengan Puskesmas Menur memperoleh capaian kunjungan K4 di tahun 2015 sebesar 71,05\% dengan total $638 \mathrm{ibu}$ hamil, meningkat pada tahun 2016 sebesar 75,90\% dengan total $592 \mathrm{ibu}$ hamil, menurun pada tahun 2017 sebesar 66,93\% dengan total $587 \mathrm{ibu}$ hamil.

Hasil observasi diperoleh dari Unit Sistem Informasi Kesehatan khususnya pemegang data program KIA Dinas Kesehatan Kota Surabaya. Hasil tersebut menunjukkan bahwa ada beberapa permasalahan yang bisa mengakibatkan target dari cakupan kunjungan K4 tidak tercapai. Hal ini dikarenakan masih terdapat laporan kunjungan K4 hardfile (hasil dalam bentuk kertas) yang tidak sesuai dengan data softfile (hasil yang ada pada komputer).

Tabel 1. Tren Kunjungan Ibu Hamil K4 di Tiga Puskesmas yang Menurun dari Tahun 2015-2017 Kota Surabaya

\begin{tabular}{ccccc}
\hline Kecamatan & Puskesmas & 2015 (\%) & 2016(\%) & 2017 (\%) \\
\hline Bubutan & Tembok Dukuh & 73,04 & 62,51 & 69,42 \\
Simokerto & Tambak Rejo & 77,04 & 61,69 & 64,14 \\
Sukolilo & Menur & 71,05 & 75,90 & 66,9 \\
\hline
\end{tabular}


Permasalahan yang menjadi penyebab tidak tercapainya target capaian kunjungan K4 perlu dilakukan identifikasi. Cakupan kunjungan $\mathrm{K} 4$ yang belum memenuhi target juga perlu dilakukan monitoring dan evaluasi dari pemegang program kesehatan yang telah atau sedang dilakukan (Izati \& Notobroto, 2019). Hal ini bertujuan untuk mengetahui akar dari permasalahan target kunjungan K4 yang tidak tercapai. Identifikasi penyebab masalah didapatkan dari Unit Sistem Informasi Kesehatan (SIK) Dinas Kesehatan Kota Surabaya khususnya pemegang data program KIA.

Identifikasi yang dilakukan untuk mengetahui ketidaksesuaian capaian kunjungan K4 di laporan kunjungan K4 hardfile (hasil dalam bentuk kertas) yang tidak sesuai dengan data softfile (hasil yang ada pada komputer) disebabkan adanya kurang ketelitian dalam pengisian laporan. Hal tersebut dapat menyebabkan cakupan kunjungan K4 kurang dari target. Penyebab lain yaitu ketidaksesuaian format data laporan dan kesalahan dalam pencetakan laporan dari pihak Puskesmas, sehingga terjadi pengembalian laporan oleh Dinas Kesehatan Kota Surabaya ke pihak puskesmas untuk dilakukan perbaikan.

Kesalahan yang terjadi merupakan bagian dari kelengkapan sarana dan prasarana dalam menunjang kualitas kunjungan ibu hamil. Hal tersebut dikarenakan terdapat beberapa laporan yang menggunakan sistem pencatatan dan pelaporan secara manual (Wiranti, Nurhayati dan Sistiarani, 2013). Penelitian lain menyebutkan cakupan kunjungan K4 yang tidak memenuhi target atau terjadi kesalahan pencatatan dikarenakan tidak semua ibu hamil melakukan pemeriksaan kehamilan di masing-masing bidan setempat (Hidayah, Handayani dan Indriyanti, 2016).

Laporan kunjungan ibu hamil K4 Puskesmas yang rendah diketahui pada saat dilakukan pengecekan laporan. Hal ini disebabkan karena ada tempat pelayanan kesehatan di wilayah kerja puskesmas yang tidak diambil data kunjungan ibu hamil K4, sehingga cakupan yang didapat di puskesmas rendah. Cakupan kunjungan K4 yang rendah diketahui ketika dilakukan validasi antara pemegang program di bidang Kesehatan Masyarakat dengan Puskesmas.

\section{PEMBAHASAN}

\section{Gambaran Laporan Cakupan Kunjungan Ibu Hamil K4 di Dinas Kesehatan Kota Surabaya}

Hasil olah statistik menunjukkan bahwa hasil capaian yang tidak signifikan antara capaian puskesmas tertinggi dan terendah dari 63 puskesmas di Kota Surabaya pada tahun 20152017. Capaian yang melebihi $100 \%$ maka perlu dilihat lagi proses dan pengolahannya terutama pada proses validasi dan perhitungan pasien dalam dan luar wilayah (Trijayanti, 2011).

Pada Tabel 1 menunjukkan bahwa dari 63 puskesmas terdapat tiga puskesmas yang memperoleh capaian kunjungan ibu hamil K4 yang kurang dari target Rencana Strategi (Renstra) Dinas Kesehatan Kota Surabaya. Tiga Puskesmas yang kurang dari target secara berurutturut pada tahun 2015-2017 yaitu Puskesmas Tembok Dukuh, Puskesmas Tambakrejo dan Puskesmas Menur. Penyebab cakupan kunjungan ibu hamil K4 di Kota Surabaya yang masih mengalami penurunan maupun tidak stabil dalam pencapaiannya bisa terjadi karena kesalahan dalam mekanisme pelaporan baik dalam input data, proses pengolahan data, dan outputnya (Dharmawan, Wigati dan Dwijayanti, 2015).

Masukan (input) merupakan sesuatu yang dibutuhkan untuk dapat melaksanakan sistem manajemen. Data yang di input oleh puskesmas dengan tren kunjungan K4 rendah di Surabaya kemungkinan terdapat kesalahan dalam penulisan yang kurang tepat pada laporan dan masih ada yang kurang lengkap. Data yang telah di input akan diberikan ke Dinas Kesehatan Kota Surabaya.

Sistem Informasi Kesehatan (SIK) pada sistem manajemen di Dinas Kesehatan Kota Surabaya memerlukan input yang dimasukkan pada data cakupan kunjungan ibu hamil K4. Data yang dimasukkan berupa data laporan dari puskesmas yang harus dikumpulkan secara lengkap dan tepat waktu.

Proses (process) merupakan bagian manajemen Sistem Informasi Kesehatan yakni mengubah masukan menjadi keluaran yang direncanakan. Proses untuk memperoleh hasil dari pelaporan kunjungan K4 di Kota Surabaya dilakukan di Sistem Informasi Kesehatan pada 
Dinas Kesehatan Kota Surabaya. Proses yang dilakukan berupa pengumpulan dan inventaris data serta pengolahan data. Hal ini dilakukan agar data mengenai cakupan kunjungan ibu hamil K4 di Kota Surabaya dapat dikeluarkan sehingga memuat sebuah informasi.

Keluaran (output) yaitu hasil dari suatu sistem manajemen. Unit SIK di Dinas Kesehatan Kota Surabaya menghasilkan output berupa Profil Kesehatan Kota Surabaya, Laporan Tahunan, Kebutuhan Sekretariat, Kebutuhan Kepala Dinas Kesehatan. Keluaran tersebut di dalamnya memuat informasi mengenai cakupan kunjungan ibu hamil K4. Informasi atau output laporan kunjungan K4 ibu hamil yang dihasilkan oleh Dinas Kesehatan Kota Surabaya masih terdapat ketidakakuratan pada laporan PWS KIA dan tidak tepat waktu dikarenakan pengolahan masih dikerjakan dengan cara manual, sehingga laporan kunjungan K4 memungkinkan terjadi kesalahan.

Laporan kunjungan K4 kemungkinan terjadi kesalahan dikarenakan kualitas informasi yang didapatkan pada sistem pelaporan kunjungan K4. Suatu sistem informasi kesehatan rutin berbasis manual mempunyai beberapa kelemahan, antara lain kualitas data dan informasi yang minim (Zainal, Sanjaya dan Hasanbasri, 2013). Sistem pelaporan kunjungan K4 di Kota Surabaya menghasilkan informasi dalam berbagai laporan sesuai kebutuhan. Informasi yang dihasilkan memiliki kualitas informasi yang dipengaruhi oleh 3 hal pokok. Kualitas informasi tersebut antara lain akurasi (accurasy), informasi yang akurat apabila informasi yang tersedia dapat dipercayai, benar mengenai informasinya dan dapat menjelaskan maksud dari informasi dan tujuan informasinya (Depkes RI, 2010).

Beberapa hal dapat mempengaruhi keakuratan sebuah informasi yaitu pertama, informasi yang akurat memiliki kelengkapan data yang baik. Hasil informasi tentu dapat mempengaruhi dalam pengambilan keputusan. Keakuratan informasi akan mempengaruhi kemampuan pengguna dalam melakukan kontrol terhadap suatu masalah dengan cara yang tepat. Kedua, hasil informasi dari data yang diolah harus memiliki kebenaran yang sesuai dengan perhitungan. Ketiga, informasi yang diberikan harus tetap aman dari bentuk gangguan yang mungkin dapat merubah atau merusak keakurasian dari informasi sehingga informasi yang dihasilkan sesuai dengan tujuan utama (Mulyanto, 2009).

Keakurasian data dari laporan kunjungan K4 dipengaruhi kelengkapan data. Kelengkapan data cakupan kunjungan K4 di Puskesmas yang ada di Surabaya dibutuhkan dari data kunjungan ibu hamil di seluruh tempat pelayanan kesehatan yang ada di Surabaya. Kelengkapan dalam pencatatan cakupan kunjungan ibu hamil K4 di Kota Surabaya perlu diperhatikan agar informasi yang didapat terkait kunjungan ibu hamil K4 dapat diketahui dan di deteksi sedini mungkin. Hal ini perlu dilakukan upaya pemenuhan pelayanan kesehatan pada ibu hamil.

Kelengkapan data pada laporan kunjungan K4 diperoleh dari laporan PWS KIA di puskesmas. Kelengkapan data kunjungan K4 di puskesmas dilihat dari banyaknya laporan ibu hamil yang memeriksakan kehamilannya di tempat pelayanan kesehatan di wilayah kerja puskesmas. Data yang diolah meliputi data pelayanan yang dilaporkan rutin oleh bidan yang terdiri dari data laporan kunjungan K4 Ibu Hamil.

Kualitas informasi yang didapat dari laporan kunjungan K4 di Kota Surabaya juga dipengaruhi oleh ketepatan waktu. Ketepatan waktu (timeliness) juga merupakan hal pokok dari kualitas informasi. Ketepatan waktu menggambarkan cepat atau lambatnya pelaksanaan tahapan-tahapan dalam sistem surveillans untuk mengidentifikasi masalah kesehatan (Wijayanti, 2016). Informasi dihasilkan dari ketepatan dalam pengolahan data. Data laporan kunjungan K4 yang diperoleh dari puskesmas di Kota Surabaya yang akan menjadi informasi yang buruk apabila tidak dilakukan tepat waktu. Hal ini karena informasi menjadi landasan dalam mengambil keputusan. Ketepatan waktu puskesmas yang ada di Surabaya untuk memberikan laporan kunjungan K4 ke Dinas Kesehatan Kota Surabaya dilakukan paling lambat tanggal 10 di tiap bulan. Laporan tersebut memuat cakupan kunjungan ibu hamil K4.

Ketepatan waktu tidak dapat dilaksanakan jika masih terjadi kesalahan baik dalam 
kelengkapan data maupun dalam pencetakan data. Ketepatan waktu dilihat dari pengumpulan laporan, penanggulangan kasus yang teridentifikasi dan penyebaran informasi (Rani \& Hargono, 2014).

Kualitas informasi dari laporan cakupan kunjungan K4 di Kota Surabaya juga dipengaruhi oleh relevansi. Informasi dari laporan kunjungan K4 dapat dikatakan berkualitas jika relevan bagi pemakai informasinya. Relevansi informasi bagi setiap orang dengan yang lainnya berbeda. Relevansi sistem pelaporan cakupan kunjungan K4 yang dihasilkan berupa Profil Kesehatan Kota Surabaya, Laporan Tahunan, Kebutuhan Sekretariat, Kebutuhan Kepala Dinas Kesehatan dan lain-lain.

Cakupan kunjungan ibu hamil K4 dapat terlihat baik apabila data yang dilaporkan memiliki akurasi, kelengkapan data, tepat waktu dan relevan. Hal ini sesuai penelitian yang dilakukan oleh Ingan Taringan bahwa kualitas pelaporan belum baik apabila pelaporan belum dilakukan tepat waktu dan tidak dilakukan secara rutin serta berdasarkan sisi pemanfaatan data dapat mencapai 33\% standar kualitasnya (Tarigan, 2009).

\section{SIMPULAN DAN SARAN}

\section{Simpulan}

Cakupan kunjungan ibu hamil K4 tahun 2014-2017 di Dinas Kesehatan Kota Surabaya diketahui telah berhasil, namun puskesmas yang terendah cakupan kunjungan ibu hamil K4 termasuk puskesmas yang masih kurang dari target Dinas Kesehatan Kota Surabaya 98,45\% untuk tahun 2017. Puskemas dengan tren kunjungan ibu hamil $\mathrm{K} 4$ cenderung menurun dan kurang dari target $98,45 \%$ yang telah ditetap pada Rencana Strategis (Renstra) Dinas Kesehatan Kota Surabaya. Tiga puskesmas yang menurun dari tahun 2014-2017 yaitu Puskemas Tembok Dukuh, Puskesmas Simokerto, dan Puskesmas Menur.

Penyebab laporan cakupan kunjungan ibu hamil K4 di Kota Surabaya yang masih mengalami penurunan maupun ketidakstabilan dalam pencapaiannya bisa dikarenakan kesalahan dalam mekanisme pelaporan baik dalam input data, proses pengolahan data, dan outputnya. Hal lain yang dapat menyebabkan tren pada laporan kunjungan $\mathrm{K} 4$ rendah yaitu pada kualitas informasi yang didapatkan pada sistem pelaporan kunjungan K4. Kualitas yang diperoleh dipengaruhi oleh 3 hal pokok yaitu akurasi dari data laporan kunjungan $\mathrm{K} 4$, ketepatan waktu memberikan laporan kunjungan K4 ke Dinas Kesehatan Kota Surabaya, dan relevansi dari laporan cakupan kunjungan K4.

\section{Saran}

Dinas Kesehatan Kota Surabaya perlu mengadakan pengembangan sistem informasi pada pencatatan dan pelaporan. Khususnya mengenai pelayanan kesehatan ibu terutama ibu hamil di puskesmas agar pencatatan dan pelaporan dapat di minimalisir ketidak lengkapan dan kesalahannya, baik input, proses, maupun output. Hal tersebut dilakukan agar dapat memudahkan dalam penyajian data yang terkait pengambilan keputusan yang tepat dan cepat serta menghasilkan informasi yang berkualitas baik untuk digunakan meningkatkan pelayanan kesehatan ibu hamil. Selain itu juga memberikan arahan penanggungjawab KIA di puskesmas untuk melakukan evaluasi terlebih dahulu mengenai kualitas informasi dari laporan kunjungan K4. Evaluasi dilakukan sesuai dengan wilayah kerjanya sebelum laporan diterima oleh Sistem Informasi Kesehatan (SIK) di Dinas Kesehatan Kota Surabaya.

Rekomendasi yang diberikan diharapkan agar pengelolaan Laporan Kunjungan K4 Puskesmas di Dinas Kesehatan Kota Surabaya dapat terselesaikan. Hal tersebut bertujuan agar informasi yang keluar dapat dipahami dengan kualitas informasi yang baik dan bermanfaat.

\section{DAFTAR PUSTAKA}

Depkes RI, 2010. Sistem Informasi Kesehatan. Jakarta: Departemen Kesehatan Republik Indonesia.

Dharmawan, Y., Wigati, P.A., Dwijayanti, F., 2015. Kinerja Petugas dalam Pencatatan dan Pelaporan PWS KIA di Puskesmas Duren. Jurnal Kesehatan Masyarakat, 10(2), pp.210-217. 
Diana, A., Setiawati, L., 2011. Sistem Informasi Akuntansi, Perencanaan, Prosedur dan Penerapan. 1st ed. Yogyakarta: Andi.

Dinkes Kota Surabaya, 2016. Profil Kesehatan Kota Surabaya Tahun 2015. Surabaya: Dinas Kesehatan Kota Surabaya.

Dinkes Kota Surabaya, 2017. Profil Kesehatan Kota Surabaya Tahun 2016. Surabaya: Dinas Kesehatan Kota Surabaya.

Dinkes Kota Surabaya, 2018. Profil Kesehatan Kota Surabaya Tahun 2017. Surabaya: Dinas Kesehatan Kota Surabaya.

Dinkes Provinsi Jawa Timur, 2017. Profil Kesehatan Provinsi Jawa Timur Tahun 2016. Surabaya: Dinas Kesehatan Provinsi Jawa Timur.

Hidayah, L., Handayani, O.W.K., Indriyanti, D.R., 2016. Pelayanan Kesehatan Maternal dalam Akselerasi Penurunan Maternal Mortality. Public Health Perspective Journal, 1(1), pp.35-43.

Izati, A.R.M., 2018. Trend Cakupan Kunjungan Ibu Hamil (K4) dan Pertolongan Persalinan oleh Tenaga Kesehatan di Provinsi Jawa Timur. Jurnal Ilmiah Kesehatan Media Husada, 7(1), pp.1-10.

Izati, A.R.M., Notobroto, H.B., 2019. Penerapan Metode Artificial Neural Network dalam Peramalan Jumlah Kunjungan Ibu Hamil (K4). Jurnal Biometrika dan Kependudukan, 8(1), pp.11-20.

Kemenkes RI, 2018. Profil Kesehatan Republik Indonesia Tahun 2017. Jakarta: Kementerian Kesehatan Republik Indonesia.

Keputusan Menteri Kesehatan Nomor 004 Tahun 2003 Tentang Kebijakan dan Strategi Desentralisasi Bidang Kesehatan. Jakarta: Kementerian Kesehatan Republik Indonesia.

Keputusan Menteri Kesehatan Nomor 932 Tahun 2002 Tentang Petunjuk Pelaksanaan Pengembangan Sistem Informasi Kesehatan Kabupaten/Kota. Jakarta: Kementerian Kesehatan Republik Indonesia.

Krismiaji, 2015. Sistem Informasi Akuntansi. Yogyakarta: Sekolah Tinggi Ilmu Manajemen YKPN.
Maharani, R., Sulistyo, T., 2016. Penelitian Non Reaktif dan Analisis Data Sekunder. Semarang: Universitas Diponegoro.

Mulyanto, A., 2009. Sistem Informasi Konsep dan Aplikasi. Yogyakarta: Pustaka Pelajar.

Peraturan Menteri Kesehatan Republik Indonesia Nomor 43 Tahun 2016 Tentang Standar Pelayanan Minimal Bidang Kesehatan. Jakarta: Kementerian Kesehatan Republik Indonesia.

Rani, I.A., Hargono, A., 2014. Deskripsi Pencatatan dan Pelaporan Pemantauan Kesehatan Ibu pada PWS-KIA Berdasarkan Atribut Surveilan. Jurnal Berkala Epidemiologi, 2(1), pp.3447.

Tarigan, I., 2009. Kualitas Data Imunisasi Rutin Berdasarkan Metode Data Quality Self Assessment (DQS). Media Litbang Kesehatan, 19(1), pp.15-24.

Trijayanti, L., 2011. Sistem Informasi Pencatatan dan Pelaporan Pelayanan Kesehatan Ibu Tahun 2010 di UPT Puskesmas Sukmajaya Kota Depok. Skripsi. Universitas Indonesia.

WHO, 2010. Health Information Systems. [online] Available at: $<$ https://www.who.int/healthinfo/ systems/WHO_MBHSS_2010_section3_web. pdf $>$.

Wijayanti, B., 2016. Deskripsi Pemantauan Kesehatan Anak pada Sistem PWS-KIA di Puskesmas Ranuyoso Lumajang. Jurnal Berkala Epidemiologi, 4(2), pp.151-163.

Wiranti, B.S., Nurhayati, S., Sistiarani, C., 2013. Analisis Tren Cakupan Kunjungan Ulang Ibu Hamil (K4) di Wilayah Kerja Puskesmas Kabupaten Banyumas Tahun 2010. Jurnal Kesmasindo, 6(2), pp.94-109.

Zainal, Y., Sanjaya, G.Y., Hasanbasri, M., 2013. Perlunya Sistem Informasi dalam Mengelola Data Rutin untuk Monitoring Kesehatan Ibu dan Anak. In: Seminar Nasional Sistem Informasi Indonesia (SESINDO) Bali 2-4 Desember 2013. pp.273-279. 